\title{
Gamma Interferon Enhances the Killing of Staphylococcus aureus by Human Neutrophils
}

\author{
By STEVEN W. EDWARDS, * JANE E. SAY AND VALERIE HUGHES \\ Department of Biochemistry, University of Liverpool, PO Box 147, Liverpool L69 3BX, UK
}

(Received 16 July 1987; revised 9 September 1987)

\begin{abstract}
The effect of purified human interferon- $\gamma$ on the responsiveness of human neutrophils was investigated. Pre-incubation of neutrophils with $100 \mathrm{U}$ interferon $\mathrm{ml}^{-1}$ for $10 \mathrm{~min}$ at $37^{\circ} \mathrm{C}$ resulted in a $2 \cdot 5$-fold increase in $N$-formylmethionyl-leucyl-phenylalanine-stimulated reactive oxygen metabolite generation (as assayed by luminol-dependent chemiluminescence). Pretreatment of neutrophils with interferon also potentiated their ability to kill Staphylococcus aureus, and thus it is proposed that this lymphokine may also enhance neutrophil function in vivo under certain pathological conditions.
\end{abstract}

\section{INTRODUCTION}

Polymorphonuclear leucocytes (neutrophils) are phagocytic cells of the immune system which provide the first line of defence in the protection of the host against microbial pathogens. In order to fulfil this role, neutrophils possess a battery of cytotoxic enzymes and associated pathways which are activated or released into the phagocytic vesicle formed after the ingestion of micro-organisms by phagocytosis (Klebanoff \& Clark, 1978; Karnovsky \& Bolis, 1982). A key event in this killing process is the generation of a series of reactive oxidants during a respiratory burst of non-mitochondrial $\mathrm{O}_{2}$ uptake (Babior, 1978, 1984; Rossi, 1986), although some pathogens can be killed by bactericidal components whose activity is independent of the requirement for molecular $\mathrm{O}_{2}$ (Elsbach \& Weiss, 1983; Spitznagel, 1984; Vel et al., 1984; Thore et al., 1985).

Whilst neutrophils will respond in vitro to a wide variety of chemical and particulate stimuli, considerable interest has focused recently on designing experimental systems which closely simulate their behaviour during acute inflammation. For example, during an inflammatory response neutrophils must be signalled to leave the bloodstream, migrate to the inflamed/infected site and then phagocytose pathogens. During this process, neutrophils are exposed to gradients of a wide variety of inflammatory mediators which may alter their responsiveness prior to their arrival at the inflammatory site. Neutrophils can be 'primed' in vitro by low concentrations (usually 10-fold lower than those necessary for activation per se) of inflammatory mediators so that their activity upon subsequent exposure to such agents is considerably enhanced (McCall et al., 1979; Van Epps \& Garcia, 1980; English et al., 1981; Bender et al., 1983; McPhail et al., 1984; Dewar \& Baggiolini, 1985).

Interferon- $\gamma$ (immune interferon, INF- $\gamma$ ), which is produced during antigenic or mitogenic stimulation of T lymphocytes (Friedman, 1981; Smalley \& Borden, 1986), can also modulate the responsiveness of mature, bloodstream neutrophils (Shalaby et al., 1985; Hockland \& Berg, 1981; Basham et al., 1984). Some wide-ranging effects have been described, including enhanced antibody-dependent or -independent cell-mediated cytotoxicity (Steinbeck et al., 1986; Perussia et al., 1987) and increased potential to generate reactive oxidants (Berton et al., 1986). Since we have shown that the killing of the bacterium Staphylococcus aureus by human neutrophils is

Abbreviations: FMLP, $N$-formylmethionyl-leucyl-phenylalanine; INF- $\gamma$, interferon- $\gamma$. 
crucially dependent upon the generation of reactive oxidants (Edwards et al., 1987), the aim of the present study was to determine whether the bactericidal activity of neutrophils towards this organism was enhanced by exposure to INF- $\gamma$.

\section{METHODS}

Isolation and purification of neutrophils. Neutrophils were prepared from heparinized venous blood from healthy volunteers, either by a combined dextran/Ficoll sedimentation procedure (Edwards \& Swan, 1986), or by centrifugation through M-PRM (Flow Laboratories), as described previously (Edwards et al., 1987). After purification they were suspended in Krebs/HEPES buffer, containing (mM): $\mathrm{NaCl}, 120 ; \mathrm{KCl}, 4 \cdot 8 ; \mathrm{KH}_{2} \mathrm{PO}_{4}, 4 \cdot 8$; $\mathrm{CaCl}_{2}, 1 \cdot 3 ; \mathrm{MgSO}_{4}, 1 \cdot 2$; HEPES, 25 (pH 7.4); and $0.1 \%$ bovine serum albumin.

Growth and opsonization of bacteria. Staphylococcus aureus was grown overnight on nutrient agar plates at $37^{\circ} \mathrm{C}$. Cells were then scraped from the plates, suspended in sterile phosphate-buffered saline (PBS, containing $0 \cdot 15 \mathrm{M}$ $\mathrm{NaCl}, 10 \mathrm{mM}-\mathrm{KH}_{2} \mathrm{PO}_{4}, \mathrm{pH} \mathrm{7.4)}$ and the number of viable cells was estimated by measurement of $\mathrm{OD}_{550}$, using suitable calibration curves. Opsonization using pooled serum from healthy donors (stored in portions at $-20^{\circ} \mathrm{C}$ ) was achieved by incubating bacteria $\left(5 \times 10^{8} \mathrm{ml}^{-1}\right)$ with $10 \%$ serum $\left(\mathrm{v} / \mathrm{v}\right.$, final concn) for 30 min at $37^{\circ} \mathrm{C}$ (Turner et al., 1986), prior to the addition of 3 vols chilled, sterile PBS and whirlimixing for $30 \mathrm{~s}$. After this, the opsonized bacteria were centrifuged at $1000 \mathrm{~g}$ for $15 \mathrm{~min}$ in an MSE Centaur 2 centrifuge, washed three times in PBS and finally suspended to known concentration.

Bacterial killing. Neutrophils were suspended in Krebs/HEPES buffer to $10^{6}$ cells $\mathrm{ml}^{-1}$ at $37^{\circ} \mathrm{C}$. At time zero, pre-opsonized bacteria were added (final concn $3-4 \times 10^{7} \mathrm{ml}^{-1}$ ) and then samples were aseptically removed at frequent time intervals. These samples were diluted 100 -fold in sterile double-distilled water, whirlimixed for 5 min to lyse the neutrophils and then diluted in sterile saline. The number of viable bacteria was then estimated by spread-plating suitably diluted samples onto nutrient agar and incubating overnight at $37^{\circ} \mathrm{C}$.

Incubations with interferon. Purified human INF- $\gamma$ was diluted in sterile PBS and stored in portions (at a

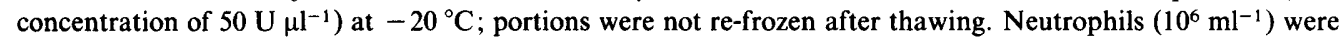
incubated with various concentrations of INF- $\gamma$ at $37^{\circ} \mathrm{C}$ for various lengths of time prior to assay. In all experiments, neutrophil suspensions incubated for identical periods in the absence of INF- $\gamma$ served as controls.

Chemiluminescence measurements. Chemiluminescence was measured in $1 \mathrm{ml}$ samples containing $10 \mu \mathrm{M}-1 \mathrm{mminol}$ using an LKB 1250 luminometer. In all experiments the neutrophil concentration was $10^{6} \mathrm{cells} \mathrm{ml}^{-1}$ and the temperature of operation was $37^{\circ} \mathrm{C}$.

Chemicals. Luminol (5-amino-2,3-dihydro-1,4-phthalazinedione), purified human INF- $\gamma$, HEPES and $N$ formylmethionyl-leucyl-phenylalanine (FMLP) were from Sigma. All other chemicals were of the highest purity available.

\section{RESULTS}

\section{Effect of INF- $\gamma$ on FMLP-stimulated chemiluminescence}

In order to determine whether pre-treatment of neutrophils with INF- $\gamma$ enhanced either their ability to generate reactive oxidants or their bactericidal activity towards $S$. aureus, it was first necessary to establish the conditions required for maximal potentiation of neutrophil responsiveness. This was achieved by pre-incubating neutrophils with INF- $\gamma$ and determining the effect on FMLP-stimulated reactive oxidant generation as assayed by luminol-dependent chemiluminescence (Edwards, 1987). Neutrophils incubated with INF- $\gamma$ at concentrations up to $50 \mathrm{U} \mathrm{ml}^{-1}$ for $10 \mathrm{~min}$ prior to the addition of FMLP exhibited only a small increase in chemiluminescence response compared to control suspensions incubated under identical conditions in the absence of INF- $\gamma$ (Fig. 1). However, at concentrations of INF- $\gamma>50 \mathrm{U} \mathrm{ml}^{-1}$, a more pronounced effect on FMLP-stimulated chemiluminescence was observed; maximal enhancement $\left(2 \cdot 5\right.$-fold increase) occurred at $100 \mathrm{U} \mathrm{ml}^{-1}$.

The addition of INF- $\gamma$ at any concentration tested did not stimulate neutrophil chemiluminescence per se and a pre-incubation time of $>2$ min was necessary before any effect on FMLP-stimulated chemiluminescence was observed (Fig. 2). However, as the pre-incubation time with $100 \mathrm{U}$ INF- $\gamma \mathrm{ml}^{-1}$ was increased, so the potentiation of the chemiluminescence response increased; the maximal effect was observed when FMLP was added 10 min after the addition of INF- $\gamma$. Representative chemiluminescence traces showing the enhancement obtained by pre-incubation of neutrophils with $100 \mathrm{U} \mathrm{INF}-\gamma \mathrm{ml}^{-1}$ for $10 \mathrm{~min}$ prior to the addition of FMLP are shown in Fig. 3. 


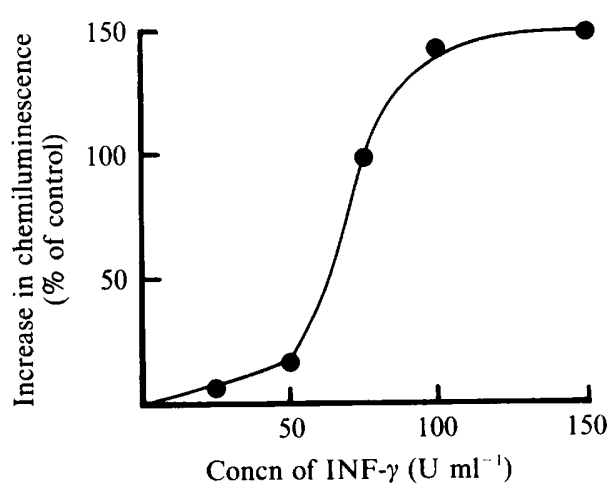

Fig. 1

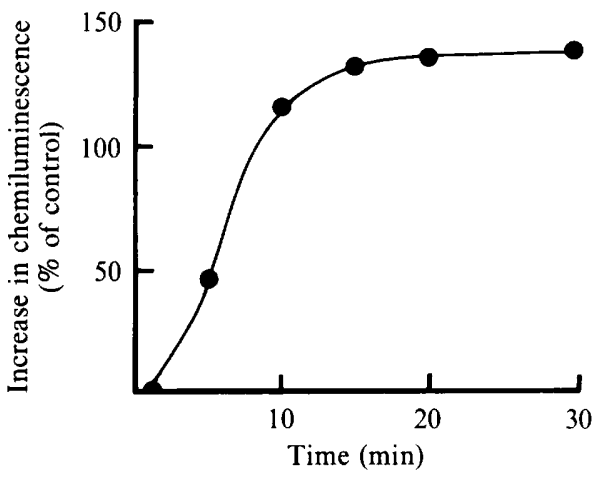

Fig. 2

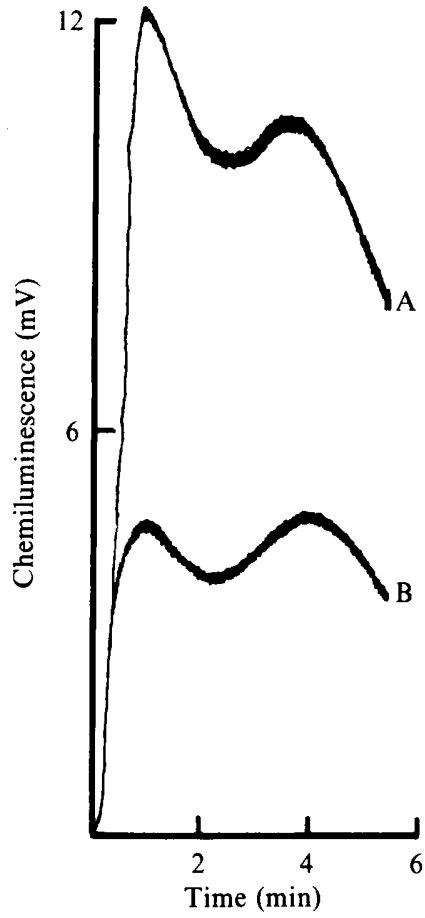

Fig. 3

Fig. 1. Effect of INF- $\gamma$ on FMLP-stimulated chemiluminescence. Neutrophils $\left(10^{6} \mathrm{ml}^{-1}\right.$, total volume $1 \mathrm{ml}$ ) were incubated at $37^{\circ} \mathrm{C}$ for $10 \mathrm{~min}$ in buffer containing $10 \mu \mathrm{M}$-luminol and varying concentrations of INF- $\gamma$. The tubes were then transferred to the luminometer, $1 \mu \mathrm{M}$-FMLP was added (final concn) and the chemiluminescence response was recorded. Data presented have been corrected for the chemiluminescence response obtained in control suspensions incubated under identical conditions in the absence of INF- $\gamma$ prior to stimulation by FMLP. A $100 \%$ increase in chemiluminescence represents a doubling in response. Data presented are typical of those obtained in four separate experiments.

Fig. 2. Time course of INF- $\gamma$ enhancement of chemiluminescence. Neutrophil suspensions $\left(10^{6} \mathrm{ml}^{-1}\right.$, total volume $\left.1 \mathrm{ml}\right)$ were incubated at $37^{\circ} \mathrm{C}$ in buffer containing $10 \mu \mathrm{M}$-luminol in the presence or absence of $100 \mathrm{UINF}-\gamma \mathrm{ml}^{-1}$. After incubation for various times, the tubes were transferred to the luminometer and the chemiluminescence response was measured after the addition of $1 \mu \mathrm{M}$ FMLP (final concn). Data presented are corrected for the chemiluminescence responses obtained in FMLP-stimulated suspensions which were incubated for the equivalent times in the absence of INF- $\gamma$. Similar results were obtained in three other experiments.

Fig. 3. Typical chemiluminescence traces for the experiments described in the legends to Figs 1 and 2 after the addition of $1 \mu \mathrm{M}$-FMLP (final concn) to neutrophil suspensions which had been incubated for $10 \mathrm{~min}$ at $37^{\circ} \mathrm{C}$ in the presence (A) or absence (B) of $100 \mathrm{U} \mathrm{INF}-\gamma \mathrm{ml}^{-1}$.

\section{Effect of INF- $\gamma$ on killing of $S$. aureus}

Having established that pre-incubation of neutrophils with $100 \mathrm{U} \mathrm{INF}-\gamma \mathrm{ml}^{-1}$ for $10 \mathrm{~min}$ resulted in maximal potentiation of FMLP-stimulated chemiluminescence, it was then necessary to determine whether this treatment also enhanced their bactericidal activity towards $S$. aureus. Neutrophils were incubated for $10 \mathrm{~min}$ in the presence or absence of $100 \mathrm{U}$ INF- $\gamma$ $\mathrm{ml}^{-1}$ prior to the addition of pre-opsonized bacteria. The incubation mixtures were then sampled at timed intervals and viable bacteria estimated. In the absence of INF- $\gamma$, the numbers 


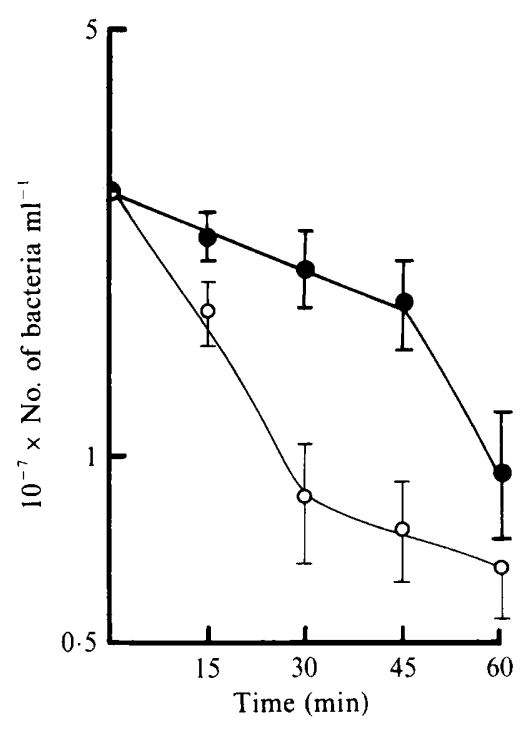

Fig. 4

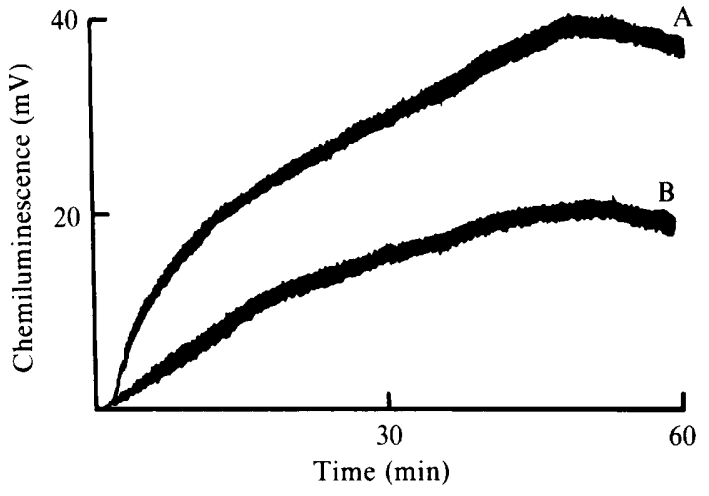

Fig. 5

Fig. 4. Effect of INF- $\gamma$ on the killing of $S$. aureus by neutrophils. Neutrophil suspensions $\left(10^{6} \mathrm{ml}^{-1}\right.$, total volume $1 \mathrm{ml}$ ) were incubated for $10 \mathrm{~min}$ at $37^{\circ} \mathrm{C}$ in the presence $(O)$ or absence (O) of $100 \mathrm{U}$ INF$\gamma \mathrm{ml}^{-1}$. After this incubation period, $3 \times 10^{7}$ pre-opsonized $S$. aureus were added to each tube and at timed intervals samples were removed for the estimation of viable bacteria, as described in Methods. Data presented are mean values, \pm standard deviations, of at least seven separate experiments.

Fig. 5. Effect of INF- $\gamma$ on chemiluminescence during phagocytosis of $S$. aureus. Experimental details as described in the legend to Fig. 4 except that suspensions contained $10 \mu \mathrm{M}$-luminol. After the addition of bacteria, tubes were transferred to the luminometer and the chemiluminescence traces recorded. Neutrophil suspensions were pre-incubated for $10 \mathrm{~min}$ at $37^{\circ} \mathrm{C}$ in the presence (A) or absence (B) of $100 \mathrm{U} \mathrm{INF}-\gamma \mathrm{ml}^{-1}$. Similar chemiluminescence traces were obtained in five separate experiments.

of viable bacteria in the suspension rapidly decreased, and $1 \mathrm{~h}$ after addition only $30 \%$ of the original inoculum remained viable (Fig. 4). However, when neutrophils were pre-incubated with INF- $\gamma$ prior to the addition of bacteria, their bactericidal activity was potentiated so that the bacteria were killed much more rapidly than in control suspensions. For example, in control suspensions $30 \%(\mathrm{SD} \pm 10 \%, n=7)$ of the bacteria were killed by 30 min whereas with INF- $\gamma$ treated neutrophils $70 \%( \pm 8 \%, n=8)$ had been killed by this time; after 60 min incubation there was little difference in the numbers of viable bacteria remaining in control and INF- $\gamma$ treated suspensions. Representative traces showing the chemiluminescence responses obtained during phagocytosis of $S$. aureus by control or INF- $\gamma$-treated neutrophils are shown in Fig. 5: the chemiluminescence response of INF- $\gamma$-treated cells was about twice that of control suspensions.

\section{DISCUSSION}

The data presented here clearly demonstrate that pre-treatment of mature, bloodstream neutrophils with $100 \mathrm{U} \mathrm{INF}-\gamma \mathrm{ml}^{-1}$ for $10 \mathrm{~min}$ greatly increases their ability to generate reactive oxidants induced either by exposure to the chemotactic peptide FMLP or during phagocytosis of pre-opsonized $S$. aureus. Furthermore, pre-treatment of neutrophils with this lymphokine also potentiated their ability to kill these bacteria, with over twice as many killed within 30 min after phagocytosis as compared with control suspensions (Fig. 4). This increase in bactericidal activity represented an increase in the initial rate of killing, since the final numbers of bacteria killed were the same in INF- $\gamma$-treated and control suspensions. We have shown that killing of $S$. aureus by human neutrophils is crucially dependent upon the generation of oxidants (Edwards $e t$ 
al., 1987), and the results presented here are consistent with this: thus conditions which enhance the ability of neutrophils to generate oxidants also enhance their ability to kill $S$. aureus.

This ability of INF- $\gamma$ to enhance neutrophil responsiveness appears similar to the 'priming' effects which have been described with other inflammatory mediators. However, in contrast to agents such as FMLP which can 'prime' or 'activate' neutrophils depending on the concentration used, we could not demonstrate 'activation' per se by INF- $\gamma$ at any concentration employed in the present study.

Whereas previous studies have shown that INF- $\gamma$ can exert a number of effects on mature neutrophil function, none have described those reported here. For example, Berton et al. (1986) showed that incubation of neutrophils with recombinant INF- $\gamma$ at concentrations of 20 $50 \mathrm{U} \mathrm{ml}^{-1}$ for 2-4 h was necessary for potentiation of superoxide generation, and Perussia et al. (1987) have shown that this lymphokine can protect against the deterioration of neutrophil function which normally accompanies incubation at $37^{\circ} \mathrm{C}$. Recombinant bovine INF- $\gamma$ was able to enhance both antibody-dependent and -independent cell-mediated cytotoxicity after $2.5 \mathrm{~h}$ incubation with bovine neutrophils, but no effect of the ability to ingest $S$. aureus or to generate superoxide was observed (Steinbeck et al., 1986). We show here, for the first time, that pre-incubation of human neutrophils with INF- $\gamma$ for periods as short as $10 \mathrm{~min}$ potentiates their bactericidal activity towards $S$. aureus. Furthermore, luminol-dependent chemiluminescence is similarly enhanced by pre-incubation of neutrophils with this lymphokine for 2-10 min. Since we have shown that efficient killing of $S$. aureus by human neutrophils requires activation of reactive oxidant generation (Edwards et al., 1987), we propose that the enhancement of killing induced by INF- $\gamma$ resides in the increased ability of neutrophils to generate these oxidants. Further work is necessary to determine the molecular mechanisms underlying this increased bactericidal activity and whether this process involves the NADPH oxidase and/or myeloperoxidase.

Understanding the mechanisms involved during the modulation of the immune response by lymphokines and cytokines is essential if we are to exploit the potential therapeutic advantage offered by these naturally occurring compounds. The observation that INF- $\gamma$ potentiates the rate of killing of $S$. aureus, and of Blastomyces dermatitidis (Morrison et al., 1987), by neutrophils in vitro suggests that this lymphokine may be of use clinically in the therapy of infections mediated by these organisms.

We thank the Arthritis and Rheumatism Council for generous financial support.

\section{REFERENCES}

BABIOR, B. M. (1978). Oxygen-dependent microbial killing by phagocytes. New England Journal of Medicine 298, 659-668.

BABIOR, B. M. (1984). Oxidants from phagocytes: agents of defence and destruction. Blood 64, 959966.

Basham, T. Y., Smith, W. K. \& Merigan, T. C. (1984). Interferon enhances antibody-dependent cellular cytotoxicity when suboptimal concentrations of antibody are used. Cellular Immunology 88, 393-400.

Bender, J. G., McPhail, L. C. \& VAN Epps, D. E. (1983). Exposure of human neutrophils to chemotactic factors potentiates activation of the respiratory burst enzyme. Journal of Immunology 130, 23162323.

Berton, G., Zeni, L., Cassatella, M. A. \& Rossi, F. (1986). Gamma interferon is able to enhance the oxidative metabolism of human neutrophils. Biochimica et biophysica acta 138, 1276-1282.

Dewar, B. \& Baggiolini, M. (1985). Activation of NADPH oxidase in human neutrophils. Synergism between $\mathrm{MLLP}$ and the neutrophil products PAF and $\mathrm{LTB}_{4}$. Biochemical and Biophysical Research Communications 128, 297-304.
EDWARDS, S. W. (1987). Luminol- and lucigenindependent chemiluminescence of neutrophils: role of degranulation. Journal of Clinical and Laboratory Immunology 22, 35-39.

EDWARDS, S. W. \& SWAN, T. F. (1986). Regulation of superoxide generation by myeloperoxidase during the respiratory burst of human neutrophils. Biochemical Journal 237, 601-604.

Edwards. S. W., Say, J. E. \& Hart, C. A. (1987). Oxygen-dependent killing of Staphylococcus aureus by human neutrophils. Journal of General Microbiology 133, 3591-3597.

ElsBaCh, P. \& Weiss, J. (1983). A reevaluation of the roles of the $\mathrm{O}_{2}$-dependent and $\mathrm{O}_{2}$-independent microbial systems of phagocytes. Reviews of Infectious Diseases 5, 843-853.

English, D., Roloff, J. S. \& Lukens, J. N. (1981). Chemotactic factor enhancement of superoxide release from fluoride and phorbol myristate acetate stimulated neutrophils. Blood 58, 129-134.

FrIEDMAN, R. M. (1981). Interferons. In Cellular Functions in Immunity and Inflammation, pp. 283300. Edited by J. J. Oppenheim, D. L. Rosenstreich \& M. Potter. London: Edward Arnold. 
HOCKLAND, P. \& BERG, K. (1981). Interferon enhances the antibody-dependent cellular cytotoxicity (ADCC) of human polymorphonuclear leukocytes. Journal of Immunology 127, 1585-1588.

KaRnovsKy, M. L. \& Bolis, L. (editors) (1982). Phagocytosis - Past and Future. London \& New York: Academic Press.

Klebanoff, S. J. \& Clark, R. A. (1978). The Neutrophil: Function and Clinical Disorders. Amsterdam: North-Holland.

McCall, C. E., Bass, D. A., DeChatelet, L. R., LINK, A. S. L. JR. \& MUNN, M. (1979). In vitro responses of human neutrophils to $N$-formyl-methionyl-leucyl-phenylalanine: correlation with effects of acute bacterial infection. Journal of Infectious Diseases 140, 277-286.

McPhail, L. C., Clayton, C. C. \& Snyderman, R. (1984). The NADPH oxidase of human polymorphonuclear leukocytes. Evidence for regulation by multiple signals. Journal of Biological Chemistry 259, 5768-5775.

Morrison, C. J., Brummer, E., Isenberg, R. A. \& Stevens, D. A. (1987). Activation of murine polymorphonuclear neutrophils for fungicidal activity by recombinant gamma interferon. Journal of Leukocyte Biology 41, 434-440.

Perussia, B., Kobayashi, M., Rossi, M. E., Anegon, I. \& TRINCHIERI, G. (1987). Immune interferon enhances functional properties of human granulocytes: role of $F c$ receptors and effect of lymphotoxin, tumour necrosis factor, and granulocyte-macrophage colony-stimulating factor. Journal of Immuno$\log y$ 138, 765-774.

Rossi, F. (1986). The $\mathrm{O}_{2}^{-}$-forming NADPH oxidase of the phagocytes: nature, mechanisms of activation and function. Biochimica et biophysica acta 853, 6589.

Shalaby, M. R., AgGarwal, B. B., Rinderknecht,
E., Svedersky, L. P., Finkle, B. S. \& Palladino, M. A., JR (1985). Activation of human polymorphonuclear neutrophil functions by interferon- $\gamma$ and tumour necrosis factors. Journal of Immunology 135 , 2069-2073.

SMAlley, R. V. \& BoRden, E. C. (1986). Interferons: current status and future directions of this prototypic biological. Springer Seminars in Immunopathology 9 , 73-84.

SPITZNAGEL, J. K. (1984). Nonoxidative antimicrobial reactions in leukocytes. In Regulation of Leukocyte Function (Contemporary Topics in Immunobiology vol. 14), pp. 283-343. Edited by R. Snyderman. New York: Plenum.

Steinbeck, M. J., Roth, J. A. \& Kaeberle, M. L. (1986). Activation of bovine neutrophils by recombinant interferon- $\gamma$. Cellular Immunology 98, 137144.

Thore, M., Lofgren, S., Tarnvick, A., Monsen, T., Selstam, E. \& Burman, L. G. (1985). Anaerobic phagocytosis, killing, and degranulation of Streptococcus pneumoniae by human peripheral blood leukocytes. Infection and Immunity 47, 277-281.

Turner, M. W., Grant, C., Seymour, N. D., HARVEY, B. \& LEVINSKY, R. J. (1986). Evaluation of $\mathrm{C} 3 \mathrm{~b} / \mathrm{C} 3 \mathrm{bi}$ opsonization and chemiluminescence with selected yeasts and bacteria using sera of different opsonic potential. Immunology 58, 111-115.

VAN EPPS, D. E. \& GaRCIA, M. L. (1980). Enhancement of neutrophil function as a result of prior exposure to chemotactic factor. Journal of Clinical Investigation 56, 167-175.

Vel, W. A. C., Namavar, F., Verweij, A. M. J. J., Pubben, A. N. B. \& Maclaren, D. M. (1984). Killing capacity of human polymorphonuclear leukocytes in aerobic and anaerobic conditions. Journal of Medical Microbiology 18, 173-180. 